

\title{
Studying the recoveries of four representative organophosphorus pesticides from eighteen plant products belonging to different botanical categories; implications for matrix effects
}

Panagiotis R Georgakopoulos, Evaggelia Foteinopoulou, P E Athanasopoulos, Eleftherios H Drosinos, Panagiotis N Skandamis

\section{To cite this version:}

Panagiotis R Georgakopoulos, Evaggelia Foteinopoulou, P E Athanasopoulos, Eleftherios H Drosinos, Panagiotis N Skandamis. Studying the recoveries of four representative organophosphorus pesticides from eighteen plant products belonging to different botanical categories; implications for matrix effects. Food Additives and Contaminants, 2007, 24 (04), pp.360-368. 10.1080/02652030601101144 . hal00577525

\section{HAL Id: hal-00577525 \\ https://hal.science/hal-00577525}

Submitted on 17 Mar 2011

HAL is a multi-disciplinary open access archive for the deposit and dissemination of scientific research documents, whether they are published or not. The documents may come from teaching and research institutions in France or abroad, or from public or private research centers.
L'archive ouverte pluridisciplinaire HAL, est destinée au dépôt et à la diffusion de documents scientifiques de niveau recherche, publiés ou non, émanant des établissements d'enseignement et de recherche français ou étrangers, des laboratoires publics ou privés. 


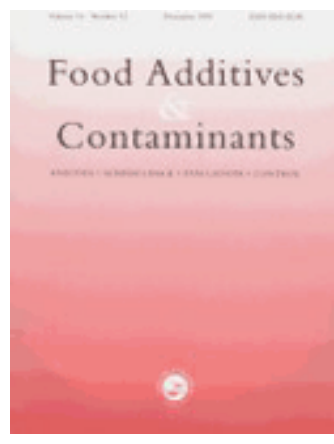

\section{Studying the recoveries of four representative organophosphorus pesticides from eighteen plant products belonging to different botanical categories; implications for matrix effects}

\begin{tabular}{|r|l|}
\hline Journal: & Food Additives and Contaminants \\
\hline Manuscript ID: & TFAC-2006-206.R1 \\
\hline Manuscript Type: & Original Research Paper \\
\hline Author: & 23-Oct-2006 \\
\hline Complete List of Authors: & $\begin{array}{l}\text { Georgakopoulos, Panagiotis; Agricultural University of Athens, Food } \\
\text { Science and Technology } \\
\text { Foteinopoulou, Evaggelia; Agricultural University of Athens, Food } \\
\text { Science and Technology } \\
\text { Athanasopoulos, P; Agricultural University of Athens, Food Science } \\
\text { and Technology } \\
\text { Drosinos, Eleftherios; Agricultural University of Athens, Food } \\
\text { Science and Technology } \\
\text { Skandamis, Panagiotis; Agricultural University of Athens, Food } \\
\text { Science and Technology }\end{array}$ \\
\hline Methods/Techniques: & Chromatography - GC \\
\hline Additives/Contaminants: & Pesticides - organophosphorous \\
\hline Food Types: & Fruit, Vegetables \\
\hline
\end{tabular}

\section{SCHOLARONE Manuscripts}


Studying the recoveries of four representative organophosphorus pesticides from eighteen plant products belonging to different botanical categories; implications

\section{Abstract}

A study of the matrix effect was performed in order to evaluate the influence of some matrices on the gas chromatographic responses of representative organophosphorus

9 insecticides. Particularly, 3 fortification levels and the Maximum Residual Level 10 (MRL) of 4 organophosphorus pesticide standard solutions were added in 18 matrices 11 (15 belonging to 5 specific botanical categories and 3 botanically unclassified). The 12 recoveries of the examined pesticides were determined using a simple official 13 multiresidue method of detection, without any additional clean-up step. Recoveries 14 were estimated based on standards prepared in solvent. The recovery percentages of 15 the most polar pesticides, especially methamidophos (20.2-288.4\%), were much 16 higher than those of non polar ones (chlorpyrifos and methidathion $25.7-136.4 \%$ and 17 37.6-292.6\% respectively), except for quince. Pronounced matrix effects $(>120 \%)$ 18 were observed to the lowest fortification levels (MRLs established by EU), of 19 dimethoate and methamidophos (i.e. the most polar analytes) in the majority of 20 product extracts. Furthermore, it was proved that there is no correlation between the 21 classification of plant products, according to their botanical characteristics, and the 22 recoveries of pesticides in the equivalent extracts. Indeed, there were significant 23 differences in the recoveries of pesticides in extracts, derived from matrices belonging 24 to the same botanical group (especially in the categories of pome fruits and citrus). 25 Consequently, it was shown that, under the examined conditions, obtaining recovery 
26 data, derived from only one representative matrix, with purpose to validate an official

27 method in its botanical category is, possibly, an erroneous practice.

28

29 Keywords: matrix effect, organophosphorus pesticide residue analysis, ethyl acetate,

30 botanical groups, validation. 
Introduction

32 Bearing in mind the prevalence of chemical pest control and the wide variety of pesticides available, the monitoring of pesticides residues constitutes a prevalent objective in chemical contaminants research that aims mainly to prevent possible risks the influence of each matrix examined on the analysis. Particularly, there have been

52 observed differences in the pesticides recovery depending on the solvent used in the 53 sample preparation (Maštovská and Lehotay 2004). In addition, the 54 quantification/recovery of the most important analytes by gas chromatography is 55 strongly affected by various factors, including the efficiency of the extraction method 
56 and a phenomenon, known as "matrix-induced chromatographic response 57 enhancement", which was first described by Erney et al. (1993), and causes 58 excessively high recovery results. This phenomenon takes place during analysis of 59 samples that contain a wide range of matrix components (e.g. pigments, waxes, lipids 60 and other non volatile constituents) that may remain after the preparation of the 61 sample and the additional step of clean-up (Godula et al. 1999). Such compounds liner (Erney et al. 1993). accumulate in the GC inlet and/or in the front part of a capillary column. Particularly, during analysis of a pesticide(s) standard solution, more active sites in the injection liner are available for the certain analyte(s), compared to those available during analysis of a sample containing also matrix components (Schenck and Lehotay 2000). This is due to the fact that the latter components block the active sites of injection

Consequently, matrix effect is considered, nowadays, as one of the most persistent sources of uncertainty in pesticide residue analysis (Cuadros-Rodriguez et al. 2002; Egea Gonzalez et al. 2002). However, available studies have focused on collecting recovery data of pesticides examining combinations of few primary crop products, many pesticides and many fortification levels (Dorea et al. 1995; Hajšlová et al. 1998). Other studies involve determination of the pesticides recovery by many products belonging only to one plant commodity group (Cai et al. 1995; Egea Gonzalez et al. 2002). Therefore, there is need to comparatively evaluate various matrices from various botanical categories per analytical method to determine the uncertainty due to matrix effect. Moreover, the recovery studies commonly involve a few matrices fortified with a mixture of pesticides. Various food matrices fortified with one pesticide should also be included in pesticide recovery studies. This would clearly illustrate the matrix effect per pesticide. 
81 The objective of this work was the evaluation of the matrix effects on the recovery

82 of four commonly applied pesticides of different physicochemical properties 83 (especially polarity), fortified in plant products of various botanical categories, at 84 three indicative levels $\left(0.2,0.5\right.$ and $\left.1.5 \mathrm{mgkg}^{-1}\right)$ and MRL (when different from the 85 fortification level studied).

\section{Materials and Methods}

Materials and Reagents

89 The solvent used was ethyl acetate (Merck, Darmstadt, Germany, 110972) and was of 90 pesticide grade. Pesticide standards (chlorpyrifos, dimethoate, methamidophos and 91 methidathion) of more than $98 \%$ purity were obtained from Chem Service (Chem

92 Service, West Chester, PA, USA). Stock solutions were prepared in ethyl acetate and 93 working standard mixtures were obtained with appropriate dilutions before use.

94 Particularly, the standards were used for the preparation of stock standard solutions 95 for each pesticide at $100 \mathrm{mgkg}^{-1}$ in the used solvent and stored at $-18^{\circ} \mathrm{C}$. In Table I, 96 there is the list of the investigated organophosphorus pesticides along with some of 97 their physicochemical characteristics (Tomlin 1997). Anhydrous sodium sulfate for 98 residue analysis was of pesticide grade (Riedel - de Haën, Hanover, Germany, 99 13464).

100 [Insert Table I about here]

101 Samples

102 Eighteen different commodities were obtained from a local market for organic

103 farming produce. Particularly, pome fruits (pears, apples and quinces), citrus (lemons, 104 mandarins and oranges), stone fruits (apricots, cherries and peaches), fruiting 105 vegetables (cucumbers, tomatoes and peppers), leafy vegetables (lettuce, spinach and 
106 chicory) and three other products not belonging to a specific group (kiwi fruits, table 107 grapes and strawberries) were used as representative matrices in the experiment.

108 These commodities were checked by gas chromatography to ensure the absence of 109 pesticide residues and their suitability for the analysis.

110 Analytical Procedure

111 All samples were prepared in triplicate by a general method suitable for gas 112 chromatography analysis with a nitrogen-phosphorus detector (NPD) (Ministry of 113 Welfare 1988). According to the method, 50g of the representative homogenized 114 sample of each commodity were mixed with $100 \mathrm{~mL}$ of ethyl acetate and $50 \mathrm{~g}$ of 115 anhydrous sodium sulfate. The mixture was blended for $2 \mathrm{~min}$ and the extract was 116 filtered through Whatman No 1 filter paper, containing approximately $5 \mathrm{~g}$ of 117 anhydrous sodium sulfate, into a conical flask. The clear filtrate, without additional 118 clean-up, was stored at $-20^{\circ} \mathrm{C}$, until it was injected into the chromatograph. The 119 storage of freezed extracts ranged from 1-4 days, so that the bounding reactions can 120 be avoided. Clean-up was not performed because the standard, by which the method 121 was adopted (Ministry of Welfare 1988), suggests that additional clean-up steps after 122 extraction are not always required for non fatty substances like fruits and vegetables, 123 and especially for the pesticides used in our study. Furthermore, the use of an 124 additional clean-up procedure may reduce the amount of co-extractives (Hajšlová et 125 al. 1998; Schenck and Lehotay 2000), and hence mask the potential effect of matrices 126 on pesticides recovery, which was the aim of our study.

127 Gas Chromatographic determination

128 A gas chromatograph (Hewlett-Packard 5890, Series II) equipped with NPD (Agilent, 129 Wilmington, USA, 19234-90167), split/splitless injector and autosampler was used. 130 The separation of sample components was performed with an $\operatorname{Rtx}^{\circledR}-5 \mathrm{~ms} 30 \mathrm{~m} x$ 
$1310.32 \mathrm{~mm}$ id $\mathrm{x} 0.25 \mu \mathrm{m}$ film thickness (Restek, USA, 12624) capillary column. The 132 injection port temperature was $260^{\circ} \mathrm{C}$ and the detector temperature $300^{\circ} \mathrm{C}$. The oven 133 temperature was programmed as follows: initial temperature $70^{\circ} \mathrm{C}$ for $1 \mathrm{~min}$, raised at $13415^{\circ} \mathrm{Cmin}^{-1}$ to $130^{\circ} \mathrm{C}$ for $0 \mathrm{~min}$, raised at $5^{\circ} \mathrm{Cmin}^{-1}$ to $230^{\circ} \mathrm{C}$ and finally raised at $13520^{\circ} \mathrm{Cmin}^{-1}$ to $250^{\circ} \mathrm{C}$ with a residence time of $13 \mathrm{~min}$. Helium carrier gas at flow rate of $1368 \mathrm{mLmin}^{-1}$ was used. Triplicate extracts $(2 \mu \mathrm{L})$ were injected and quantification of the 137 insecticides was performed by automatic integration of the peak areas (European 138 Communities 1999). Quantification/recovery of the pesticides in the fortified samples

139 was carried out by comparing the detector responses for each of the three independent 140 samples to those measured in a calibration standard, which was injected both before 141 and after each sample. It should be noticed that maintenance application of the system 142 took place at the end of a pesticide analytical "sequence", defined as the total of 143 samples prepared with one fortification level of one analyte in all 18 matrices. Product 144 extracts were analyzed in the same sequence so that the effect of matrix components 145 can be considered similar in the target analysis. Maintenance included changes 146 associated with the injection site and the front part of the chromatography column 147 being connected with the injection site. Specifically, at the end of an analytical 148 sequence, septum and injection liner were replaced and the good operation of the 149 system was evaluated by injecting the used solvent and a standard solution, containing 150 the investigated pesticides. Cutting the front part of the capillary column was decided 151 upon indications (such as peak width/height/tailing and integrated area) from the 152 injections of standard solutions. Furthermore, by the end of each sequence, $2 \mu \mathrm{L}$ of a 153 standard solution $\left(0.1 \mathrm{mgkg}^{-1}\right)$ of pesticides mixture in ethyl acetate was injected to 154 evaluate the reliability of column. In general, the performance of the GC column 155 remained satisfactory for approximately 3-4 sequences. 
156

157

158

159

160

161

162

163

164

165

166

167

168

169

170

171

172

173

174

175

176

177 found in the majority of different pesticide-matrix combinations. Specifically, every

178 product was fortified with the target pesticide solutions at the level of MRLs

179 established by EU and at fortification levels of $0.2,0.5$ and $1.5 \mathrm{mgkg}^{-1}$. The results of

180 the recovery tests are presented at Tables II-V. 
181 [Insert Tables II-V about here]

182 The type of the examined pesticides was found to influence the occurrence of

183 matrix effect $(\mathrm{p}<0.05)$, as the recoveries for the same matrix vary with the different

184 pesticides. Among the used pesticides, the highest recoveries and matrix effects were

185 observed to methamidophos and dimethoate, in the majority of product extracts

186 (especially in the lowest fortification levels). It is notable that methamidophos was not

187 detected in the first injections after the maintenance of the GC system (changing the

188 injection liner) and especially in the first samples of analysis sequence. In these cases,

189 the analysis was repeated, as multiple injections of uncleaned matrix extracts were

190 proved to have a potential effect on the NPD response in this analyte in contrast to the

191 non polar ones. Also, it was found that methamidophos recoveries were of poorer

192 precision in the three repeated injections, as it can be observed from RSDs presented

193 at Table IV. Our findings are in agreement with those of Cai et al. (1995), while

194 similar behavior has been reported for captan and other polar analytes (Hajšlová et al.

195 1998). In contrast to methamidophos and dimethoate, the lowest recovery portions

196 were observed to the non polar analytes chlorpyrifos and methidathion. However, the

197 only cases where matrix effect was observed in those analytes were: pepper in

198 fortification level $0.2 \mathrm{mgkg}^{-1}$ and strawberries (MRL) for methidathion and cucumber

199 (MRL) for chlorpyrifos (Tables II and V). These results are in agreement with Erney

200 et al. (1993), who supported that changes in the recovery portion vary with the

201 chemical structure of the pesticide and those compounds containing $\mathrm{P}=\mathrm{O}$ bonds, like 202 methamidophos, were identified as tending to give particularly high recoveries.

203 Schenck and Lehotay (2000) noticed that compounds with $\mathrm{P}=\mathrm{O}$ bonds tend to exhibit

204 more matrix effects rather than those with $\mathrm{P}=\mathrm{S}$ bonds, like the one present in the 205 molecule of dimethoate, chlorpyrifos and methidathion, because of the highest 
206 polarity of these bonds. Moreover, as it can be deduced from Table 1 regarding the 207 physicochemical properties (especially values of w.s. and $\log \mathrm{k}_{\mathrm{ow}}$, which are a degree 208 of polarity), methamidophos and dimethoate are more polar than the other two and for 209 this reason their recoveries are higher, which agrees with the statement of Hajšlová et 210 al. (1998) that the probability of the matrix effect occurrence is higher for more polar 211 pesticides.

212 The ratio of analyte and matrix concentration (fortification level) seems to be a 213 crucial point in the appearance of matrix effect, since there are differences in the 214 recovery portions between the fortification levels for the same pesticides $(\mathrm{p}<0.05)$. 215 From the results presented in Tables II-V, it can be proved that the lower is the 216 fortification level the recovery portion is higher. The phenomenon is more evident in 217 the MRLs of $0.02 \mathrm{mgkg}^{-1}$ and especially for the pesticide standard dimethoate in 218 almost all the examined matrices (Table III). This is similar to Hajšlová et al. (1998) 219 and Anastassiades et al. (2003), who noticed unacceptable recoveries and matrix 220 enhancement effects at lower concentration levels of target pesticides and/or at higher 221 matrix components. This behavior can be attributed to the lower competitive effect of 222 the pesticide standards, when they are found in trace fortification levels, for covering 223 the active sites in the injection liner (Hajšlová and Zrostlýkova 2003).

224 It was also observed that in the analysis of some matrices fortified with 225 dimethoate, methamidophos and methidathion at the MRL level, the analytes were 226 under the limit of determination, whereas in the case of other commodities fortified at 227 the same level, the analyte showed an evident peak. Specifically, dimethoate was 228 determined at the level of MRL in all matrices, apart from apricot and peach extracts. 229 Almost the same performance was obtained with methamidophos, where chicory, 230 pepper, kiwi and grapes fortified extracts gave no integrated peaks, at the MRL level 
231 of $0.01 \mathrm{mgkg}^{-1}$. In samples fortified with methidathion in the level of $0.02 \mathrm{mgkg}^{-1}$, the 232 analyte was detected only in the strawberry extract, contrary to other examined 233 matrices, as cherry, chicory, lettuce, spinach and kiwi fruit, fortified in the same level 234 of MRL. Consequently, the determination of the analyte, at the same trace level in 235 different matrices, is probably influenced by the type of the matrix. This performance 236 was not followed by chlorpyrifos, whose MRL levels are comparatively higher and all 237 peaks were easily integrated.

238 Recovery portion of pesticides also depends on the chemical composition of the 239 matrix $(p<0.05)$. It was found that the type of co-extracts that remains in the final 240 sample leads markedly to different detector response. As a consequence, the botanical 241 categories examined in the experiment can be classified according to the mean 242 recovery portions of the used pesticides (especially in the three fortification levels) in 243 the order: fruiting vegetables and table grapes $>$ strawberries and leafy 244 vegetables $>$ stone fruits and kiwi fruits $>$ pome fruits and citrus. It seems that the 245 highest recoveries were observed to samples containing more non volatile compounds 246 (such as chlorophylls in leafy vegetables, carotenoids in fruiting vegetables, waxes in 247 grapes, lipids in strawberries) compared to samples with more volatile compounds.

248 Thus, higher recoveries are possibly associated with the entrapment of non volatile 249 compounds in the injection liner which are able to cover active sites in the injection 250 liner and/or the front of analytical column and may conduct to higher recoveries. The 251 scientific evidence suggests that more distinct matrix effects have been reported for 252 extracts derived from matrices rich in pigments and lipids (Hajšlová et al. 1998; 253 Godula et al. 1999; Anastassiades et al. 2003). Also, when co-extracts, like those 254 mentioned, are accumulated in the inlet, they can create new active sites, intensifying 255 the presence of the phenomenon (Anastassiades et al. 2003). 
256 Furthermore, from Tables II-V, it can be revealed that there is no correlation 257 between the classification of plant produce by botanical characteristics and the 258 recoveries of pesticides in the respective extracts, since product extracts belonging to 259 the same botanical category present differences in the pesticides recovery. This 260 statement is more evident especially in the categories of pome fruits, in which quince 261 extracts gave extremely low recoveries in contrast with apple and pear extracts 262 (Tables II-V). Similarly in the citrus category, lemon extracts gave much higher 263 recoveries in contrast with mandarin and orange extracts $(\mathrm{p}<0.05)$ (Tables II-V). On 264 the contrary, the three examined products belonging to stone fruits and leafy 265 vegetables present smaller variations, while those belonging to fruiting vegetables 266 present unvarying behavior in the recovery portion of pesticides $(\mathrm{p}>0.05)$.

267 In the present study, there are dramatically low recoveries in pesticides in orange 268 extracts, fact opposed to other studies using ethyl acetate as the extraction solvent and 269 clean-up step (Dorea et al. 1995; Hajšlová et al. 1998). Even after the required 270 conditioning of the GC system and three months later, the analysis of the specific lot 271 (frozen oranges), with an independent extract preparation in triplicates, gave the same 272 results. On the contrary, a new lot of oranges from organic produce, analyzed by the 273 same method, gave much higher recoveries in similar combinations of pesticides and 274 fortification levels (results not shown) and the difference was more pronounce in the 275 more polar methamidophos and dimethoate at the fortification level of $1 \mathrm{mgkg}^{-1}$. 276 Probably, this behavior may be attributed to the specific lot and its different chemical 277 composition, depending on harvest time.

278 Also, it is remarkable that recoveries of pesticides in quince extracts are extremely 279 low in every pesticide and fortification level in comparison with every plant product 280 extract. The existing evidence cannot help to explain this performance, as there are no 
281 studies examining recovery data derived from quince extracts. The fact that quinces 282 contain large quantities of water-soluble pectins and the used lot was consisted of 283 immature fruits, which contained higher amounts of pectins, may be the cause of this 284 curious behavior, as it is presumed that these ingredients detain important quantities 285 of active ingredients in the extraction step.

286 Moreover, it should be noted that most matrices generally gave chromatograms 287 free of peaks in the blank extracts. Nevertheless, especially in the cases of leafy 288 vegetables and citrus extracts there were found some peaks in different retention times 289 of both the examined pesticides in this study and other organophosphorus pesticide 290 standards analyzed in our laboratory. These may be lipophilic compounds derived 291 from those matrices not removed by the extraction method, as there has been observed 292 similar behavior in uncleaned sample extracts in ethyl acetate (Cai et al. 1995; 293 Maštovská and Lehotay 2004). The fact that the same peak in orange extracts 294 appeared in every orange, either of organic produce or of conventional crop, and 295 detected in the peel orange extract analyzed itself compared to the analysis of orange 296 juice, may be the reason why some citrus peels require clean-up step, described by 297 Dorea et al. (1995).

298 Finally, it should be addressed that matrix enhancement effect is difficult to study 299 because the GC system changes as matrix components are progressively deposited in 300 the injection port and front of the analytical column (Schenck and Lehotay 2000). 301 Moreover, the injection technique has been found to play a major role on the 302 occurrence of matrix effect. Specifically, the use of cold on-column injection is 303 considered as one of the most practical approaches by which, pesticides thermolysis 304 and decomposition or adsorption inside the inlet could be avoided (Wylie 1996; 305 Godula et al. 1999). With the specific technique, more accurate results have been 
306 observed, especially for troublesome analytes, compared to splitless injection as long

307 as the chromatography system remains clean (Wylie 1996). Furthermore, it is likely

308 that polar analytes, such as methamidophos, and matrices, containing especially non

309 volatile compounds, could be analyzed by on-column injection with the parallel use of

310 a packed column or a deactivated precolumn (to keep most of the remaining matrix

311 constituents of the extract) connected to the injector site. However, the disadvantage

312 of on-column injection is that it seems to be impractical for applications of complex

313 or relatively uncleaned matrices, because it requires more maintenance of the column

314 and thus, hot splitless injection tends to be preferrable (Anastassiades et al. 2003). The

315 effect of maintenance application by changing the injection liner and/or the column is

316 also unpredictable, because as Godula et al. (1998) indicated, the history of the GC

317 system (especially changes in the injection port) plays an important role in the

318 occurrence of matrix effects. Consequently, recoveries of pesticides are not

319 reproductable and the effects of co-extracts can not be considered as stable and

320 foreseeable. For these reasons, it is better to provide recovery data and validate the

321 used method in only one produce, especially when the product is suspected for matrix

322 effects, so that the existence of matrix effect can be checked rather than providing

323 recoveries in one produce and validate the method in the whole botanical category.

324 In conclusion, the results of the present study indicate that higher pesticide

325 recoveries should be expected at more polar analytes, fortified at low concentrations

326 in matrices rich in non volatile compounds. Moreover, different recoveries may occur

327 among products of the same botanical group. Therefore, examining the recoveries of

328 target pesticides, using an official method, in only one representative plant product

329 with the purpose of validating the method for the whole botanical category is possibly

330 an erroneous practice. Indeed, the combined outcome of factors, such as analytes, 
331 matrix, and fortification level on the pesticide recovery can not always be predicted. 332 The above suggest that validation of an official method for the analysis of pesticide 333 residues should not be based only on the botanical categories of plant products. Such 334 practice may be useful, for the simplification of issuing validation, when matrix335 matched calibration standards and/or extensive clean-up of the samples are used prior 336 to the final chromatographic step. Conversely, the same practice is insuffient for 337 quantification with standards in neat solvent and/or in the final extract without 338 additional clean-up step. However, in order to further examine the analytical 339 performance of different product extracts, a matrix-matched calibration procedure for 340 each product should be severally carried out. Furthermore, the analysis of each group 341 of commodities fortified in many more levels, with a higher number of pesticides is 342 strongly recommended and may possibly explicate the differences between the 343 recovery portions of products of the same category that the current study brought out. 


\section{References}

345 Anastassiades M, Maštovská K, Lehotay SJ. 2003. Evaluation of analyte protectants 346 to improve gas chromatographic analysis of pesticides. Journal of 347 Chromatography A 1015:163-184.

348 Cai CP, Liang M, Wen RR. 1995. Rapid multiresidue screening method for 349 organophosphate pesticides in vegetables. Chromatographia 40:417-420.

350 Cuadros-Rodriguez L, Hernández Torres ME, Almansa López E, Egea González FJ, 351 Arrebola Liébanas FJ, Martinez Vidal JL. 2002. Assessment of uncertainty in 352 pesticide multiresidue analytical methods: main sources and estimation. Analytica $353 \quad$ Chimica Acta 454:297-314.

354 Dorea HS, Tadeo JL, Sanchez-Brunete C. 1995. Determination of organophosphorus 355 pesticide residues in fruits by gas chromatography with ITD and NPD detection. $356 \quad$ Chromatographia 43:380-386.

357 European Communities 1999. Commission Recommendation 99/333/EC of March 3581999 concerning a co - ordinated Community monitoring programme for 1999 to 359 ensure compliance with maximum levels of pesticide residues in and on certain 360 products of plant origin, including fruit and vegetables (OJ $\mathrm{N}^{0} 128 / 25$ of $21-05-$ 361 1999).

362 Egea González FJ, Hernández Torres ME, Cuadros Rodriguez L, Almansa López E, 363 Martinez Vidal JL. 2002. Estimation and correction of matrix effects in gas 364 chromatographic pesticide multiresidue analytical methods with a nitrogen 365 phosphorus detector. The Analyst 127:1038-1044.

366 Erney DR, Gillespie AM, Gilvydis DM, Poole CF. 1993. Explanation of the matrix 367 induced chromatographic response enhancement of organophosphorus pesticides 
368 during open tubular column gas chromatography with splitless or hot on - column 369 injection and flame photometric detection. Journal of Chromatography 638:57-63.

Godula M, Hajšlová J, Alterova K. 1999. Pulsed splitless injection and the extend of matrix effects in the analysis of pesticides. Journal of High Resolution Chromatography 22:395-402.

Hajšlová J, Holadová K, Kocourek V, Poustka J, Godula M, Cuhra P, Kempny M. 1998. Matrix - induced effects: a critical point in the gas chromatographic analysis of pesticide residues. Journal of Chromatography A 800:283-295.

Hajšlová J, Zrostlýkova J. 2003. Matrix effects in (ultra)trace analysis of pesticide residues in food and biotic matrices. Journal of Chromatography A 1000:181-197.

Hill ARC, Reynolds SL. 1999. Guidelines for in - house validation of analytical methods for pesticide residues in food and animal feeds. The Analyst 124:953958.

Maštovská K, Lehotay SJ. 2004. Evaluation of common organic solvents for gas chromatographic analysis and stability of multiclass pesticide residues. Journal of Chromatography A 1040:259-272.

Ministry of Welfare, Health and Cultural Affairs. (1988). Analytical methods for residues of pesticides in foodstuffs, edited by P. A. Greve (Rijswijk: The Netherlands), part 1, p. 3 .

Navarro M, Picó Y, Marín R, Mañes J. 2002. Application of matrix solid-phase dispersion to the determination of a new generation of pesticides in fruits and vegetables. Journal of Chromatography A 968:201-209.

Pugliese P, Moltó JC, Damiani P, Marín R, Cossignani L, Mañes J. 2004. Gas chromatographic evaluation of pesticide residue contents in nectarines after nontoxic washing treatments. Journal of Chromatography A 1050:185-191. 
393 Schenck FJ, Lehotay, SJ. 2000. Does further clean - up reduce the matrix 394 enhancement effect in gas chromatographic analysis of pesticide residues in food? 395 Journal of Chromatography A 868:51-61.

396 Tomlin CDS. 1997. The Pesticide Manual, 11th ed. London: British Crop Protection 397 Council/CRC Press.

398 Wylie PL. 1996. Improved gas chromatographic analysis of organophosphorus 399 pesticides with pulsed splitless injection. Journal of AOAC International 79:571$400 \quad 577$. 
401 Table I. Physicochemical properties of the target pesticides.

\begin{tabular}{lcccc}
\hline Pesticide & w.s. $\left(\mathbf{m g L}^{-\mathbf{1}}\right)$ & $\mathbf{l o g k}_{\mathbf{0 w}}$ & M.p. $\left({ }^{\mathbf{0}} \mathbf{C}\right)$ & V.p. $(\mathbf{m P a})$ \\
(Retention time) & & & & \\
\hline Chlorpyrifos & 1.4 & 4.7 & $42-43.5$ & 2.7 \\
$(24.6$ min) & & & \\
Dimethoate & 24000 & 0.7 & $43-45$ & 0.25 \\
(18.9 min) & & & & \\
Methamidophos & 200000 & -0.8 & 45 & 2.3 \\
(8.9 min) & & & \\
Methidathion & 200 & 2.2 & $39-40$ & 0.25 \\
(27.1 min) & & & \\
\hline
\end{tabular}

402

$403 \quad$ w.s.: water solubility $\left(20^{\circ} \mathrm{C}\right)$

$404 \quad \log \mathrm{k}_{\mathrm{ow}}$ : $\log$ of $\mathrm{n}-$ octanol partition coefficient

405 M.p.: melting point.

406 V.p.: vapour pressure $\left(25^{\circ} \mathrm{C}\right)$. 
407 Table II. Percentage recoveries and RSDs of chlorpyrifos in the different plant 408 products, classified by botanical characteristics, and in different fortification levels.

409 Bold letters designate recoveries within the acceptable range of recovery $(70-110 \%)$.

410 Values in parenthesis indicate the levels of MRLs established by EU.

\begin{tabular}{|c|c|c|c|c|}
\hline \multirow{2}{*}{ Plant products } & \multicolumn{4}{|c|}{ Recovery \pm RSD (\%) } \\
\hline & $1.5 \mathrm{mgkg}^{-1}$ & $0.5 \mathrm{mgkg}^{-1}$ & $0.2 \mathrm{mg} / \mathrm{kg}^{-1}$ & MRL $\left(\mathrm{mgkg}^{-1}\right)^{*}$ \\
\hline \multicolumn{5}{|l|}{ Pome fruits } \\
\hline - Pear & $70.1 \pm 1.1^{c}$ & $72.3 \pm 1.5^{\mathrm{b}}$ & $61.0 \pm 3.0^{\mathrm{b}}$ & $72.3 \pm 1.5(0.5)$ \\
\hline - Apple & $65.7 \pm 0.1^{\mathrm{b}}$ & $76.5 \pm 3.4^{b}$ & $92.5 \pm 15.1^{\mathrm{c}}$ & $76.4 \pm 3.4(0.5)$ \\
\hline - Quince & $46.6 \pm 1.0^{\mathrm{a}}$ & $33.4 \pm 1.2^{\mathrm{a}}$ & $25.7 \pm 17.8^{\mathrm{a}}$ & $33.4 \pm 1.2(0.5)$ \\
\hline \multicolumn{5}{|l|}{ Citrus } \\
\hline - Lemon & $61.6 \pm 1.8^{\mathrm{c}}$ & $63.6 \pm 0.8^{\mathrm{b}}$ & $85.5 \pm 1.5^{b}$ & $85.5 \pm 1.5(0.2)$ \\
\hline - Mandarin & $54.3 \pm 6.5^{\mathrm{b}}$ & $63.5 \pm 1.7^{\mathrm{b}}$ & $89.8 \pm 5.3^{b}$ & $68.2 \pm 2.8(2.0)$ \\
\hline - Orange & $44.9 \pm 5.4^{\mathrm{a}}$ & $34.2 \pm 2.7^{\mathrm{a}}$ & $36.5 \pm 5.0^{\mathrm{a}}$ & $41.4 \pm 9.8(0.3)$ \\
\hline \multicolumn{5}{|l|}{ Stone fruits } \\
\hline - Apricot & $62.4 \pm 2.3^{\mathrm{a}}$ & $51.5 \pm 2.4^{\mathrm{a}}$ & $66.5 \pm 11.0^{\mathrm{a}}$ & $65.2 \pm 13.6(0.05)$ \\
\hline - Cherry & $63.3 \pm 2.3^{\mathrm{a}}$ & $79.8 \pm 3.4^{c}$ & $67.8 \pm 2.9^{\mathrm{a}}$ & $55.4 \pm 11.8(0.3)$ \\
\hline - Peach & $62.2 \pm 0.9^{\mathrm{a}}$ & $58.3 \pm 5.0^{\mathrm{b}}$ & $70.9 \pm 10.4^{a}$ & $70.9 \pm 10.4(0.2)$ \\
\hline \multicolumn{5}{|l|}{ Leafy vegetables } \\
\hline - Lettuce & $69.2 \pm 3.4^{\mathrm{b}}$ & $78.4 \pm 3.7^{b}$ & $80.5 \pm 4.4^{\mathrm{a}}$ & $\mathbf{9 2 . 1} \pm \mathbf{5 . 8}(0.05)$ \\
\hline - Chicory & $50.6 \pm 2.6^{\mathrm{a}}$ & $68.0 \pm 3.1^{\mathrm{a}}$ & $89.8 \pm 1.6^{b}$ & $77.2 \pm 18.5(0.05)$ \\
\hline - Spinach & $75.6 \pm 2.6^{c}$ & $88.2 \pm 1.2^{c}$ & $78.0 \pm 1.4^{\mathrm{a}}$ & $89.9 \pm \mathbf{8 . 5}(0.05)$ \\
\hline \multicolumn{5}{|l|}{ Fruiting vegetables } \\
\hline - Cucumber & $71.1 \pm 2.9^{\mathrm{a}}$ & $104.9 \pm 1.9^{b}$ & $103.6 \pm 9.0^{b}$ & $136.4 \pm 11.9(0.05)$ \\
\hline - Pepper & $80.0 \pm 0.8^{a}$ & $87.1 \pm 5.5^{\mathrm{a}}$ & $108.1 \pm 9.1^{b}$ & $87.1 \pm 5.5(0.5)$ \\
\hline - Tomato & $89.2 \pm 4.6^{\mathrm{b}}$ & $80.6 \pm 2.7^{\mathrm{a}}$ & $82.5 \pm 2.8^{a}$ & $80.6 \pm 2.7(0.5)$ \\
\hline \multicolumn{5}{|l|}{ Various } \\
\hline - Kiwi fruits & $49.3 \pm 2.1$ & $54.2 \pm 6.1$ & $57.8 \pm 6.2$ & $51.5 \pm 0.9(2.0)$ \\
\hline - Table grapes & $89.5 \pm 1.1$ & $91.0 \pm 3.4$ & $97.0 \pm 9.7$ & $91.0 \pm 3.4(0.5)$ \\
\hline - Strawberries & $55.8 \pm 0.5$ & $68.0 \pm 1.8$ & $90.1 \pm 6.5$ & $90.1 \pm 6.5(0.2)$ \\
\hline
\end{tabular}

$411 \mathrm{a}, \mathrm{b}, \mathrm{c}:$ means within a plant product category and fortification level lacking a 412 common superscript letter are different $(\mathrm{p}<0.05)$. 
413 * Some MRLs are equal to one of the rest examined concentrations (i.e. 0.2 and

$\left.4140.5 \mathrm{mgkg}^{-1}\right)$. For this reason the respective recoveries appear in two columns of the 415 same row in the Table 
416 Table III. Percentage recoveries and RSDs of dimethoate in the different plant

417 products, classified by botanical characteristics, and in different fortification levels.

418 Bold letters designate recoveries within the acceptable range of recovery $(70-110 \%)$.

419 Values in parenthesis indicate the levels of MRLs established by EU.

\begin{tabular}{|c|c|c|c|c|}
\hline \multirow{2}{*}{ Plant products } & \multicolumn{4}{|c|}{ Recovery \pm RSD (\%) } \\
\hline & $1.5 \mathrm{mgkg}^{-1}$ & $0.5 \mathrm{mgkg}^{-1}$ & $0.2 \mathrm{mgkg}^{-1}$ & MRL $\left(\mathrm{mgkg}^{-1}\right)^{*}$ \\
\hline \multicolumn{5}{|l|}{ Pome fruits } \\
\hline - Pear & $90.9 \pm 1.2^{c}$ & $86.7 \pm 2.5^{\mathrm{c}}$ & $98.7 \pm 6.0^{b}$ & $118.1 \pm 6.2(0.02)$ \\
\hline - Apple & $71.6 \pm 5.0^{b}$ & $68.4 \pm 3.8^{\mathrm{b}}$ & $88.9 \pm 1.5^{b}$ & $\mathbf{9 7 . 1} \pm \mathbf{1 5 . 5}(0.02)$ \\
\hline - Quince & $22.8 \pm 3.2^{\mathrm{a}}$ & $45.1 \pm 2.8^{\mathrm{a}}$ & $28.3 \pm 12.2^{\mathrm{a}}$ & $\mathbf{1 0 3 . 0} \pm \mathbf{5 . 7}(0.02)$ \\
\hline \multicolumn{5}{|l|}{ Citrus } \\
\hline - Lemon & $84.1 \pm 6.0^{\mathrm{a}}$ & $97.4 \pm 2.9^{\mathrm{c}}$ & $97.3 \pm 3.6^{c}$ & $138.7 \pm 18.3(0.02)$ \\
\hline - Mandarin & $67.9 \pm 0.5^{\mathrm{a}}$ & $58.3 \pm 0.2^{\mathrm{a}}$ & $42.0 \pm 8.5^{\mathrm{a}}$ & $95.2 \pm 10.6(0.02)$ \\
\hline - Orange & $73.8 \pm 0.6^{a}$ & $86.8 \pm 4.9^{b}$ & $68.3 \pm 3.0^{\mathrm{b}}$ & $121.8 \pm 4.3(0.02)$ \\
\hline \multicolumn{5}{|l|}{ Stone fruits } \\
\hline - Apricot & $85.0 \pm 1.3^{\mathrm{a}}$ & $108.5 \pm 0.5^{b}$ & $113.8 \pm 3.8^{\mathrm{b}}$ & Not detected (0.02) \\
\hline - Cherry & $93.1 \pm 1.1^{b}$ & $104.7 \pm 1.4^{b}$ & $115.3 \pm 10.7^{b}$ & $90.4 \pm 2.3(1.0)$ \\
\hline - Peach & $92.4 \pm 3.7^{\mathrm{b}}$ & $78.3 \pm 0.9^{\mathrm{a}}$ & $80.5 \pm 6.6^{\mathrm{a}}$ & Not detected $(0.02)$ \\
\hline \multicolumn{5}{|l|}{ Leafy vegetables } \\
\hline - Lettuce & $92.3 \pm 1.3^{\mathrm{a}}$ & $127.4 \pm 0.6^{\mathrm{c}}$ & $116.2 \pm 3.3^{\mathrm{a}}$ & $127.4 \pm 0.6(0.5)$ \\
\hline - Chicory & $76.9 \pm 1.3^{b}$ & $112.6 \pm 0.8^{\mathrm{b}}$ & $103.3 \pm 3.5^{\mathrm{a}}$ & $138.4 \pm 5.9(0.02)$ \\
\hline - Spinach & $81.1 \pm 2.2^{\mathrm{a}}$ & $67.1 \pm 5.0^{\mathrm{a}}$ & $105.7 \pm 5.5^{\mathrm{a}}$ & $151.3 \pm 9.2(0.02)$ \\
\hline
\end{tabular}

Fruiting vegetables

- Cucumber

$88.4 \pm 1.8^{\mathrm{ab}}$

$118.1 \pm 0.5^{\mathrm{b}}$

$103.2 \pm 1.4^{\mathrm{a}}$

$157.9 \pm 14.8(0.02)$

- Pepper

$86.3 \pm 2.3^{\mathrm{b}}$

$118.8 \pm 1.3^{\mathrm{b}}$

$117.6 \pm 1.9^{\mathrm{b}}$

$137.9 \pm 5.4(0.02)$

- Tomato

$82.9 \pm 1.4^{\mathrm{a}}$

$87.1 \pm$ 6.6 $^{\mathrm{a}}$

$107.0 \pm 3.6^{\mathrm{ab}}$

$165.5 \pm 12.9(0.02)$

\section{Various}

- Kiwi fruits

$80.2 \pm 2.0$

$85.1 \pm 3.7$

$87.4 \pm 9.3$

$141.9 \pm 8.5(0.02)$

- Table grapes

$92.9 \pm 1.8$

$87.0 \pm 6.4$

$89.0 \pm 3.3$

$150.0 \pm 13.5(0.02)$

- Strawberries

$89.5 \pm 0.3$

$111.6 \pm 0.6$

$135.4 \pm 3.2$

$146.3 \pm 7.3(0.02)$

$420 \mathrm{a}, \mathrm{b}$, c: means within a plant product category and fortification level lacking a

421 common superscript letter are different $(p<0.05)$. 
422 * Some MRLs are equal to one of the rest examined concentrations (i.e. 0.2 and

$4230.5 \mathrm{mgkg}^{-1}$ ). For this reason the respective recoveries appear in two columns of the 424 same row in the Table 
425 Table IV. Percentage recoveries and RSDs of methamidophos in the different plant 426 products, classified by botanical characteristics, and in different fortification levels.

427 Bold letters designate recoveries within the acceptable range of recovery $(70-110 \%)$.

428 Values in parenthesis indicate the levels of MRLs established by EU.

\begin{tabular}{|c|c|c|c|c|}
\hline \multirow{2}{*}{ Plant products } & \multicolumn{4}{|c|}{ Recovery \pm RSD (\%) } \\
\hline & $1.5 \mathrm{mgkg}^{-1}$ & $0.5 \mathrm{mgkg}^{-1}$ & $0.2 \mathrm{mgkg}^{-1}$ & MRL $\left(\mathrm{mgkg}^{-1}\right)^{*}$ \\
\hline \multicolumn{5}{|l|}{ Pome fruits } \\
\hline - Pear & $82.3 \pm 4.8^{b}$ & $82.2 \pm 2.9^{\mathrm{b}}$ & $111.8 \pm 2.6^{\mathrm{b}}$ & $\mathbf{9 9 . 6} \pm \mathbf{5 . 8}(0.05)$ \\
\hline - Apple & $77.7 \pm 5.0^{b}$ & $93.2 \pm 11.2^{\mathrm{b}}$ & $106.3 \pm 17.8^{b}$ & Not detected $(0.05)$ \\
\hline - Quince & $32.0 \pm 4.7^{\mathrm{a}}$ & $20.2 \pm 1.8^{\mathrm{a}}$ & $38.3 \pm 10.0^{\mathrm{a}}$ & $\mathbf{8 8 . 9} \pm \mathbf{6 . 0}(0.05)$ \\
\hline \multicolumn{5}{|l|}{ Citrus } \\
\hline - Lemon & $103.6 \pm 7.7^{b}$ & $114.8 \pm 3.8^{\mathrm{b}}$ & $105.8 \pm 5.6^{\mathrm{c}}$ & $\mathbf{1 0 5 . 8} \pm \mathbf{5 . 6}(0.2)$ \\
\hline - Mandarin & $69.1 \pm 1.9^{\mathrm{a}}$ & $78.8 \pm 6.9^{\mathrm{a}}$ & $73.2 \pm 6.8^{b}$ & $73.2 \pm 6.8(0.2)$ \\
\hline - Orange & $58.2 \pm 9.3^{\mathrm{a}}$ & $63.8 \pm 6.6^{\mathrm{a}}$ & $56.8 \pm 4.3^{\mathrm{a}}$ & $56.8 \pm 4.3(0.2)$ \\
\hline \multicolumn{5}{|l|}{ Stone fruits } \\
\hline - Apricot & $88.0 \pm 12.0^{\mathrm{a}}$ & $120.6 \pm 6.3^{b}$ & $100.0 \pm 14.8^{\mathrm{a}}$ & $120.0 \pm 4.3(0.1)$ \\
\hline - Cherry & $70.9 \pm 9.5^{\mathrm{a}}$ & $79.9 \pm 7.3^{\mathrm{a}}$ & $88.5 \pm 3.7^{\mathrm{a}}$ & $166.0 \pm 15.0(0.01)$ \\
\hline - Peach & $78.8 \pm 1.4^{\mathrm{a}}$ & $83.4 \pm 1.6^{a}$ & $87.7 \pm 8.9^{a}$ & Not detected $(0.05)$ \\
\hline
\end{tabular}

Leafy vegetables

- Lettuce

$108.8 \pm 2.3^{\mathrm{b}}$

$97.7 \pm 1.5^{\mathrm{a}}$

$97.9 \pm 1.3^{\mathrm{a}}$

$97.9 \pm 1.3(0.2)$

- Chicory

$72.4 \pm 3.8^{\mathrm{a}}$

$119.3 \pm 2.8^{\mathrm{b}}$

$110.4 \pm 4.6^{\mathrm{a}}$

Not detected (0.01)

- Spinach

$98.8 \pm 9.4^{\mathrm{b}}$

$117.9 \pm 2.5^{b}$

$128.4 \pm 15.6^{\mathrm{a}}$

$288.4 \pm 2.7(0.01)$

Fruiting vegetables

- Cucumber

$96.7 \pm 13.9^{\mathrm{a}}$

$98.8 \pm 3.9^{\mathrm{a}}$

$102.1 \pm 2.2^{\mathrm{a}}$

$107.5 \pm 8.2(1.0)$

- Pepper

$82.7 \pm 2.3^{\mathrm{a}}$

$96.2 \pm 0.9^{\mathrm{a}}$

$108.2 \pm 6.4^{\mathrm{a}}$

Not detected (0.01)

- Tomato

$98.8 \pm 3.8^{\mathrm{a}}$

$96.8 \pm 0.8^{\mathrm{a}}$

$95.2 \pm 16.8^{\mathrm{a}}$

Not detected (0.05)

\section{Various}

- Kiwi fruits

$87.9 \pm 7.1$

$75.7 \pm 6.7$

$92.8 \pm 8.7$

Not detected (0.01)

- Table grapes

$76.8 \pm 4.7$

$90.0 \pm 4.1$

$91.0 \pm 5.4$

Not detected (0.01)

- Strawberries

$102.2 \pm 1.2$

$108.0 \pm 5.2$

$103.4 \pm 12.3$

$210.4 \pm 3.5(0.01)$

$\mathrm{a}, \mathrm{b}, \mathrm{c}:$ means within a plant product category and fortification level lacking a

430 common superscript letter are different $(\mathrm{p}<0.05)$. 
$431 *$ Some MRLs are equal to one of the rest examined concentrations (i.e. 0.2 and

$4320.5 \mathrm{mgkg}^{-1}$ ). For this reason the respective recoveries appear in two columns of the 433 same row in the Table 
434 Table V. Percentage recoveries and RSDs of methidathion in the different plant 435 products, classified by botanical characteristics, and in different fortification levels.

436 Bold letters designate recoveries within the acceptable range of recovery $(70-110 \%)$.

437 Values in parenthesis indicate the levels of MRLs established by EU.

\begin{tabular}{|c|c|c|c|c|}
\hline \multirow{2}{*}{ Plant products } & \multicolumn{4}{|c|}{ Recovery \pm RSD (\%) } \\
\hline & $1.5 \mathrm{mgkg}^{-1}$ & $0.5 \mathrm{mgkg}^{-1}$ & $0.2 \mathrm{mgkg}^{-1}$ & MRL $\left(\mathrm{mgkg}^{-1}\right)^{*}$ \\
\hline \multicolumn{5}{|l|}{ Pome fruits } \\
\hline - Pear & $69.8 \pm 1.4^{b}$ & $62.1 \pm 3.1^{\mathrm{b}}$ & $74.4 \pm 1.6^{b}$ & $74.2 \pm 7.2(0.3)$ \\
\hline - Apple & $81.9 \pm 2.9^{c}$ & $77.2 \pm 2.8^{c}$ & $90.8 \pm 1.0^{c}$ & $\mathbf{8 8 . 8} \pm \mathbf{1 . 9}(0.3)$ \\
\hline - Quince & $40.5 \pm 0.8^{\mathrm{a}}$ & $40.2 \pm 2.2^{\mathrm{a}}$ & $46.0 \pm 1.7^{\mathrm{a}}$ & $73.6 \pm 10.8(0.3)$ \\
\hline \multicolumn{5}{|l|}{ Citrus } \\
\hline - Lemon & $79.7 \pm 0.3^{\mathrm{c}}$ & $86.1 \pm 1.6^{b}$ & $73.0 \pm 6.4^{b}$ & $81.9 \pm 8.7(2.0)$ \\
\hline - Mandarin & $59.1 \pm 2.8^{\mathrm{a}}$ & $40.7 \pm 0.4^{\mathrm{a}}$ & $44.6 \pm 13.1^{\mathrm{a}}$ & $61.2 \pm 5.1(2.0)$ \\
\hline - Orange & $44.4 \pm 0.8^{\mathrm{b}}$ & $37.6 \pm 5.4^{\mathrm{a}}$ & $44.8 \pm 14.2^{\mathrm{a}}$ & $53.2 \pm 4.5(2.0)$ \\
\hline \multicolumn{5}{|l|}{ Stone fruits } \\
\hline - Apricot & $70.9 \pm 2.5^{\mathrm{a}}$ & $85.9 \pm 2.8^{\mathrm{b}}$ & $100.9 \pm 4.2^{\mathrm{b}}$ & $100.9 \pm 4.2(0.2)$ \\
\hline - Cherry & $76.0 \pm 2.2^{\mathrm{a}}$ & $87.9 \pm 2.2^{b}$ & $90.5 \pm 10.4^{b}$ & Not detected (0.02) \\
\hline - Peach & $68.3 \pm 2.0^{\mathrm{a}}$ & $59.8 \pm 3.4^{\mathrm{a}}$ & $60.0 \pm 17.7^{\mathrm{a}}$ & $60.0 \pm 17.7(0.2)$ \\
\hline
\end{tabular}

Leafy vegetables

- Lettuce

$60.3 \pm 2.1^{\mathrm{a}} \quad \mathbf{7 0 . 9} \pm \mathbf{0 . 7 ^ { \mathrm { a } }}$

$76.5 \pm 13.7^{\mathrm{a}}$

Not detected (0.02)

- Chicory

$73.9 \pm 4.5^{\mathrm{b}}$

$76.2 \pm 2.4^{\mathrm{b}}$

$71.0 \pm 9.4^{\mathrm{a}}$

Not detected (0.02)

- Spinach

$53.9 \pm 1.3^{\mathrm{a}}$

$68.2 \pm 1.6^{\mathrm{a}}$

$73.9 \pm 8.6^{\mathrm{a}}$

Not detected (0.02)

Fruiting vegetables

- Cucumber

$84.8 \pm 3.4^{b}$

$106.4 \pm 4.9^{\mathrm{a}}$

$104.5 \pm 3.4^{\mathrm{a}}$

Not detected (0.02)

- Pepper

$72.0 \pm 4.1^{\mathrm{a}}$

$102.3 \pm 2.8^{\mathrm{a}}$

$112.2 \pm 0.5^{\mathrm{a}}$

Not detected (0.02)

- Tomato

$97.1 \pm 4.8^{\mathrm{c}}$

$93.9 \pm 4.0^{\mathrm{a}}$

$109.5 \pm 1.3^{\mathrm{a}}$

$109.5 \pm 1.3(0.2)$

\section{Various}

- Kiwi fruits

$58.7 \pm 3.4 \quad 53.5 \pm 4.1$

$76.6 \pm 3.7$

Not detected (0.02)

- Table grapes

$\mathbf{9 1 . 8} \pm \mathbf{2 . 8}$

$98.0 \pm 2.8$

$98.0 \pm 4.6$

$\mathbf{9 8 . 0} \pm \mathbf{2 . 8}(0.5)$

- Strawberries

$60.5 \pm 1.6$

$86.4 \pm 2.1$

$81.4 \pm 5.0$

$292.6 \pm 8.9(0.02)$

$438 \mathrm{a}, \mathrm{b}$, c: means within a plant product category and fortification level lacking a

439 common superscript letter are different $(\mathrm{p}<0.05)$. 
$440 *$ Some MRLs are equal to one of the rest examined concentrations (i.e. 0.2 and

$\left.4410.5 \mathrm{mgkg}^{-1}\right)$. For this reason the respective recoveries appear in two columns of the 442 same row in the Table 
1 Table I. Physicochemical properties of the target pesticides.

\begin{tabular}{lllll}
\hline Pesticide & w.s. $\left(\mathrm{mgL}^{-1}\right)$ & $\log \mathrm{k}_{\mathrm{ow}}$ & M.p. $\left({ }^{\circ} \mathrm{C}\right)$ & V.p. $(\mathrm{mPa})$ \\
(Retention time $)$ &
\end{tabular}

Chlorpyrifos

$\begin{array}{llll}1.4 & 4.7 & 42-43.5 & 2.7\end{array}$

(24.6 min)

Dimethoate

$(18.9 \min )$

24000

$0.7 \quad 43-45$

0.25

Methamidophos

$(8.9 \mathrm{~min})$

200000

$-0.8$

45

2.3

Methidathion

(27.1 min)

200

2.2

$39-40$

0.25

2

$3 \quad$ w.s.: water solubility $\left(20^{\circ} \mathrm{C}\right)$

$4 \quad \log \mathrm{k}_{\mathrm{ow}}: \log$ of $\mathrm{n}-$ octanol partition coefficient

$5 \quad$ M.p.: melting point.

$6 \quad$ V.p.: vapour pressure $\left(25^{\circ} \mathrm{C}\right)$. 
7 Table II. Percentage recoveries and RSDs of chlorpyrifos in the different plant

8 products, classified by botanical characteristics, and in different fortification levels.

9 Bold letters designate recoveries within the acceptable range of recovery (70-110\%).

10 Values in parenthesis indicate the levels of MRLs established by EU.

\begin{tabular}{|c|c|c|c|c|}
\hline \multirow{2}{*}{ Plant products } & \multicolumn{4}{|c|}{ Recovery \pm RSD (\%) } \\
\hline & $1.5 \mathrm{mgkg}^{-1}$ & $0.5 \mathrm{mgkg}^{-1}$ & $0.2 \mathrm{mg} / \mathrm{kg}^{-1}$ & MRL $\left(\mathrm{mgkg}^{-1}\right)^{*}$ \\
\hline \multicolumn{5}{|l|}{ Pome fruits } \\
\hline - Pear & $70.1 \pm 1.1^{c}$ & $72.3 \pm 1.5^{b}$ & $61.0 \pm 3.0^{\mathrm{b}}$ & $72.3 \pm 1.5(0.5)$ \\
\hline - Apple & $65.7 \pm 0.1^{\mathrm{b}}$ & $76.5 \pm 3.4^{b}$ & $92.5 \pm 15.1^{\mathrm{c}}$ & $76.4 \pm 3.4(0.5)$ \\
\hline - Quince & $46.6 \pm 1.0^{\mathrm{a}}$ & $33.4 \pm 1.2^{\mathrm{a}}$ & $25.7 \pm 17.8^{\mathrm{a}}$ & $33.4 \pm 1.2(0.5)$ \\
\hline \multicolumn{5}{|l|}{ Citrus } \\
\hline - Lemon & $61.6 \pm 1.8^{\mathrm{c}}$ & $63.6 \pm 0.8^{\mathrm{b}}$ & $85.5 \pm 1.5^{b}$ & $85.5 \pm 1.5(0.2)$ \\
\hline - Mandarin & $54.3 \pm 6.5^{\mathrm{b}}$ & $63.5 \pm 1.7^{\mathrm{b}}$ & $89.8 \pm 5.3^{b}$ & $68.2 \pm 2.8(2.0)$ \\
\hline - Orange & $44.9 \pm 5.4^{\mathrm{a}}$ & $34.2 \pm 2.7^{\mathrm{a}}$ & $36.5 \pm 5.0^{\mathrm{a}}$ & $41.4 \pm 9.8(0.3)$ \\
\hline \multicolumn{5}{|l|}{ Stone fruits } \\
\hline - Apricot & $62.4 \pm 2.3^{\mathrm{a}}$ & $51.5 \pm 2.4^{\mathrm{a}}$ & $66.5 \pm 11.0^{\mathrm{a}}$ & $65.2 \pm 13.6(0.05)$ \\
\hline - Cherry & $63.3 \pm 2.3^{\mathrm{a}}$ & $79.8 \pm 3.4^{c}$ & $67.8 \pm 2.9^{\mathrm{a}}$ & $55.4 \pm 11.8(0.3)$ \\
\hline - Peach & $62.2 \pm 0.9^{\mathrm{a}}$ & $58.3 \pm 5.0^{\mathrm{b}}$ & $70.9 \pm 10.4^{a}$ & $70.9 \pm 10.4(0.2)$ \\
\hline
\end{tabular}

Leafy vegetables

- Lettuce

$$
69.2 \pm 3.4^{\mathrm{b}}
$$

78.4 $\pm 3.7^{\text {b }}$

$80.5 \pm 4.4^{\mathrm{a}}$

$92.1 \pm 5.8(0.05)$

- Chicory

$50.6 \pm 2.6^{\mathrm{a}}$

$68.0 \pm 3.1^{\mathrm{a}}$

$89.8 \pm 1.6^{\mathrm{b}}$

$77.2 \pm 18.5(0.05)$

- Spinach

$\mathbf{7 5 . 6} \pm \mathbf{2 . 6 ^ { \mathrm { c } }}$

$88.2 \pm 1.2^{c}$

$78.0 \pm 1.4^{\mathrm{a}}$

$89.9 \pm 8.5(0.05)$

Fruiting vegetables

- Cucumber

$$
\begin{array}{ccrc}
\mathbf{7 1 . 1} \pm \mathbf{2 . 9}^{\mathrm{a}} & \mathbf{1 0 4 . 9} \pm \mathbf{1 . 9}^{\mathrm{b}} & \mathbf{1 0 3 . 6} \pm \mathbf{9 . 0 ^ { \mathrm { b } }} & 136.4 \pm 11.9(0.05) \\
\mathbf{8 0 . 0} \pm \mathbf{0 . 8}^{\mathrm{a}} & \mathbf{8 7 . 1} \pm \mathbf{5 . 5 ^ { \mathrm { a } }} & \mathbf{1 0 8 . 1} \pm \mathbf{9 . 1 ^ { \mathrm { b } }} & \mathbf{8 7 . 1} \pm \mathbf{5 . 5}(0.5) \\
\mathbf{8 9 . 2} \pm \mathbf{4 . 6}^{\mathrm{b}} & \mathbf{8 0 . 6} \pm \mathbf{2 . 7 ^ { \mathrm { a } }} & \mathbf{8 2 . 5} \pm \mathbf{2 . 8 ^ { \mathrm { a } }} & \mathbf{8 0 . 6} \pm \mathbf{2 . 7}(0.5)
\end{array}
$$

- Pepper

- Tomato

\section{Various}

- Kiwi fruits

$49.3 \pm 2.1$

$54.2 \pm 6.1$

$57.8 \pm 6.2$

$51.5 \pm 0.9(2.0)$

- Table grapes

$89.5 \pm 1.1$

$91.0 \pm 3.4$

$97.0 \pm 9.7$

$91.0 \pm 3.4(0.5)$

- Strawberries

$55.8 \pm 0.5$

$68.0 \pm 1.8$

$90.1 \pm 6.5$

$90.1 \pm 6.5(0.2)$

$11 \mathrm{a}, \mathrm{b}$, c: means within a plant product category and fortification level lacking a

12 common superscript letter are different $(\mathrm{p}<0.05)$. 
$13 *$ Some MRLs are equal to one of the rest examined concentrations (i.e. 0.2 and

$\left.140.5 \mathrm{mgkg}^{-1}\right)$. For this reason the respective recoveries appear in two columns of the 15 same row in the Table 
16 Table III. Percentage recoveries and RSDs of dimethoate in the different plant 17 products, classified by botanical characteristics, and in different fortification levels.

18 Bold letters designate recoveries within the acceptable range of recovery (70-110\%).

19 Values in parenthesis indicate the levels of MRLs established by EU.

\begin{tabular}{|c|c|c|c|c|}
\hline \multirow{2}{*}{ Plant products } & \multicolumn{4}{|c|}{ Recovery \pm RSD (\%) } \\
\hline & $1.5 \mathrm{mgkg}^{-1}$ & $0.5 \mathrm{mgkg}^{-1}$ & $0.2 \mathrm{mgkg}^{-1}$ & $\operatorname{MRL}\left(\mathrm{mgkg}^{-1}\right)^{*}$ \\
\hline \multicolumn{5}{|l|}{ Pome fruits } \\
\hline - Pear & $90.9 \pm 1.2^{c}$ & $86.7 \pm 2.5^{c}$ & $98.7 \pm 6.0^{b}$ & $118.1 \pm 6.2(0.02)$ \\
\hline - Apple & $71.6 \pm 5.0^{b}$ & $68.4 \pm 3.8^{\mathrm{b}}$ & $88.9 \pm 1.5^{b}$ & $97.1 \pm 15.5(0.02)$ \\
\hline - Quince & $22.8 \pm 3.2^{\mathrm{a}}$ & $45.1 \pm 2.8^{\mathrm{a}}$ & $28.3 \pm 12.2^{\mathrm{a}}$ & $\mathbf{1 0 3 . 0} \pm \mathbf{5 . 7}(0.02)$ \\
\hline \multicolumn{5}{|l|}{ Citrus } \\
\hline - Lemon & $84.1 \pm 6.0^{\mathrm{a}}$ & $97.4 \pm 2.9^{c}$ & $97.3 \pm 3.6^{c}$ & $138.7 \pm 18.3(0.02)$ \\
\hline - Mandarin & $67.9 \pm 0.5^{\mathrm{a}}$ & $58.3 \pm 0.2^{\mathrm{a}}$ & $42.0 \pm 8.5^{\mathrm{a}}$ & $95.2 \pm 10.6(0.02)$ \\
\hline - Orange & $73.8 \pm 0.6^{\mathrm{a}}$ & $86.8 \pm 4.9^{b}$ & $68.3 \pm 3.0^{\mathrm{b}}$ & $121.8 \pm 4.3(0.02)$ \\
\hline \multicolumn{5}{|l|}{ Stone fruits } \\
\hline - Apricot & $85.0 \pm 1.3^{\mathrm{a}}$ & $108.5 \pm 0.5^{\mathrm{b}}$ & $113.8 \pm 3.8^{\mathrm{b}}$ & Not detected (0.02) \\
\hline - Cherry & $93.1 \pm 1.1^{b}$ & $104.7 \pm 1.4^{b}$ & $115.3 \pm 10.7^{\mathrm{b}}$ & $90.4 \pm 2.3(1.0)$ \\
\hline - Peach & $92.4 \pm 3.7^{\mathrm{b}}$ & $78.3 \pm 0.9^{a}$ & $80.5 \pm 6.6^{\mathrm{a}}$ & Not detected $(0.02)$ \\
\hline \multicolumn{5}{|l|}{ Leafy vegetables } \\
\hline - Lettuce & $92.3 \pm 1.3^{\mathrm{a}}$ & $127.4 \pm 0.6^{c}$ & $116.2 \pm 3.3^{\mathrm{a}}$ & $127.4 \pm 0.6(0.5)$ \\
\hline - Chicory & $76.9 \pm 1.3^{b}$ & $112.6 \pm 0.8^{\mathrm{b}}$ & $103.3 \pm 3.5^{\mathrm{a}}$ & $138.4 \pm 5.9(0.02)$ \\
\hline - Spinach & $81.1 \pm 2.2^{\mathrm{a}}$ & $67.1 \pm 5.0^{\mathrm{a}}$ & $105.7 \pm 5.5^{\mathrm{a}}$ & $151.3 \pm 9.2(0.02)$ \\
\hline
\end{tabular}

Fruiting vegetables

- Cucumber

$88.4 \pm 1.8^{\mathrm{ab}}$

$118.1 \pm 0.5^{\mathrm{b}}$

$103.2 \pm 1.4^{\mathrm{a}}$

$157.9 \pm 14.8(0.02)$

- Pepper

$86.3 \pm 2.3^{b}$

$118.8 \pm 1.3^{\mathrm{b}}$

$117.6 \pm 1.9^{\mathrm{b}}$

$137.9 \pm 5.4(0.02)$

- Tomato

$82.9 \pm 1.4^{\mathrm{a}}$

$87.1 \pm$ 6.6 $^{\mathrm{a}}$

$107.0 \pm 3^{2} 6^{\mathrm{ab}}$

$165.5 \pm 12.9(0.02)$

\section{Various}

- Kiwi fruits

$80.2 \pm 2.0$

$85.1 \pm 3.7$

$87.4 \pm 9.3$

$141.9 \pm 8.5(0.02)$

- Table grapes

$92.9 \pm 1.8$

$87.0 \pm 6.4$

$89.0 \pm 3.3$

$150.0 \pm 13.5(0.02)$

- Strawberries

$89.5 \pm 0.3$

$111.6 \pm 0.6$

$135.4 \pm 3.2$

$146.3 \pm 7.3(0.02)$

20 a, b, c: means within a plant product category and fortification level lacking a

21 common superscript letter are different $(\mathrm{p}<0.05)$. 
$22 *$ Some MRLs are equal to one of the rest examined concentrations (i.e. 0.2 and

$230.5 \mathrm{mgkg}^{-1}$ ). For this reason the respective recoveries appear in two columns of the

24 same row in the Table 
25 Table IV. Percentage recoveries and RSDs of methamidophos in the different plant 26 products, classified by botanical characteristics, and in different fortification levels.

27 Bold letters designate recoveries within the acceptable range of recovery $(70-110 \%)$.

28 Values in parenthesis indicate the levels of MRLs established by EU.

\begin{tabular}{|c|c|c|c|c|}
\hline \multirow{2}{*}{ Plant products } & \multicolumn{4}{|c|}{ Recovery \pm RSD (\%) } \\
\hline & $1.5 \mathrm{mgkg}^{-1}$ & $0.5 \mathrm{mgkg}^{-1}$ & $0.2 \mathrm{mgkg}^{-1}$ & MRL $\left(\mathrm{mgkg}^{-1}\right)^{*}$ \\
\hline \multicolumn{5}{|l|}{ Pome fruits } \\
\hline - Pear & $82.3 \pm 4.8^{b}$ & $82.2 \pm 2.9^{b}$ & $111.8 \pm 2.6^{\mathrm{b}}$ & $99.6 \pm 5.8(0.05)$ \\
\hline - Apple & $77.7 \pm 5.0^{b}$ & $93.2 \pm 11.2^{\mathrm{b}}$ & $106.3 \pm 17.8^{b}$ & Not detected $(0.05)$ \\
\hline - Quince & $32.0 \pm 4.7^{\mathrm{a}}$ & $20.2 \pm 1.8^{\mathrm{a}}$ & $38.3 \pm 10.0^{\mathrm{a}}$ & $88.9 \pm \mathbf{6 . 0}(0.05)$ \\
\hline \multicolumn{5}{|l|}{ Citrus } \\
\hline - Lemon & $103.6 \pm 7.7^{b}$ & $114.8 \pm 3.8^{\mathrm{b}}$ & $105.8 \pm 5.6^{c}$ & $\mathbf{1 0 5 . 8} \pm \mathbf{5 . 6}(0.2)$ \\
\hline - Mandarin & $69.1 \pm 1.9^{\mathrm{a}}$ & $78.8 \pm 6.9^{\mathrm{a}}$ & $73.2 \pm 6.8^{\mathrm{b}}$ & $73.2 \pm 6.8(0.2)$ \\
\hline - Orange & $58.2 \pm 9.3^{\mathrm{a}}$ & $63.8 \pm 6.6^{\mathrm{a}}$ & $56.8 \pm 4.3^{\mathrm{a}}$ & $56.8 \pm 4.3(0.2)$ \\
\hline \multicolumn{5}{|l|}{ Stone fruits } \\
\hline - Apricot & $88.0 \pm 12.0^{\mathrm{a}}$ & $120.6 \pm 6.3^{b}$ & $100.0 \pm 14.8^{\mathrm{a}}$ & $120.0 \pm 4.3(0.1)$ \\
\hline - Cherry & $70.9 \pm 9.5^{\mathrm{a}}$ & $79.9 \pm 7.3^{\mathrm{a}}$ & $88.5 \pm 3.7^{\mathrm{a}}$ & $166.0 \pm 15.0(0.01)$ \\
\hline - Peach & $78.8 \pm 1.4^{\mathrm{a}}$ & $83.4 \pm 1.6^{\mathrm{a}}$ & $87.7 \pm 8.9^{a}$ & Not detected $(0.05)$ \\
\hline
\end{tabular}

Leafy vegetables

- Lettuce

$108.8 \pm 2.3^{\mathrm{b}}$

$97.7 \pm 1.5^{\mathrm{a}}$

$97.9 \pm 1.3^{\mathrm{a}}$

$97.9 \pm 1.3(0.2)$

- Chicory

$72.4 \pm 3.8^{\mathrm{a}}$

$119.3 \pm 2.8^{\mathrm{b}}$

$110.4 \pm 4.6^{\mathrm{a}}$

Not detected (0.01)

- Spinach

$98.8 \pm 9.4^{\mathrm{b}}$

$117.9 \pm 2.5^{\mathrm{b}}$

$128.4 \pm 15.6^{\mathrm{a}}$

$288.4 \pm 2.7(0.01)$

Fruiting vegetables

- Cucumber

$96.7 \pm 13.9^{\mathrm{a}}$

$98.8 \pm 3.9^{\mathrm{a}}$

$102.1 \pm 2.2^{\mathrm{a}}$

$107.5 \pm 8.2(1.0)$

- Pepper

$82.7 \pm 2.3^{\mathrm{a}}$

$96.2 \pm 0.9^{\mathrm{a}}$

$108.2 \pm 6.4^{\mathrm{a}}$

Not detected (0.01)

- Tomato

$98.8 \pm 3.8^{\mathrm{a}}$

$96.8 \pm 0.8^{\mathrm{a}}$

$95.2 \pm 16.8^{\mathrm{a}}$

Not detected (0.05)

\section{Various}

- Kiwi fruits

$87.9 \pm 7.1$

$75.7 \pm 6.7$

$92.8 \pm 8.7$

Not detected (0.01)

- Table grapes

$76.8 \pm 4.7$

$90.0 \pm 4.1$

$91.0 \pm 5.4$

Not detected (0.01)

- Strawberries

$102.2 \pm 1.2$

$108.0 \pm 5.2$

$103.4 \pm 12.3$

$210.4 \pm 3.5(0.01)$

$\mathrm{a}, \mathrm{b}, \mathrm{c}$ : means within a plant product category and fortification level lacking a

30 common superscript letter are different $(\mathrm{p}<0.05)$. 
$31 *$ Some MRLs are equal to one of the rest examined concentrations (i.e. 0.2 and

$320.5 \mathrm{mgkg}^{-1}$ ). For this reason the respective recoveries appear in two columns of the

33 same row in the Table 
34 Table V. Percentage recoveries and RSDs of methidathion in the different plant

35 products, classified by botanical characteristics, and in different fortification levels.

36 Bold letters designate recoveries within the acceptable range of recovery $(70-110 \%)$.

37 Values in parenthesis indicate the levels of MRLs established by EU.

\begin{tabular}{|c|c|c|c|c|}
\hline \multirow{2}{*}{ Plant products } & \multicolumn{4}{|c|}{ Recovery \pm RSD (\%) } \\
\hline & $1.5 \mathrm{mgkg}^{-1}$ & $0.5 \mathrm{mgkg}^{-1}$ & $0.2 \mathrm{mgkg}^{-1}$ & MRL $\left(\mathrm{mgkg}^{-1}\right)^{*}$ \\
\hline \multicolumn{5}{|l|}{ Pome fruits } \\
\hline - Pear & $69.8 \pm 1.4^{b}$ & $62.1 \pm 3.1^{\mathrm{b}}$ & $74.4 \pm 1.6^{b}$ & $74.2 \pm 7.2(0.3)$ \\
\hline - Apple & $81.9 \pm 2.9^{c}$ & $77.2 \pm 2.8^{c}$ & $90.8 \pm 1.0^{c}$ & $88.8 \pm 1.9(0.3)$ \\
\hline - Quince & $40.5 \pm 0.8^{\mathrm{a}}$ & $40.2 \pm 2.2^{\mathrm{a}}$ & $46.0 \pm 1.7^{\mathrm{a}}$ & $73.6 \pm 10.8(0.3)$ \\
\hline \multicolumn{5}{|l|}{ Citrus } \\
\hline - Lemon & $79.7 \pm 0.3^{c}$ & $86.1 \pm 1.6^{b}$ & $73.0 \pm 6.4^{b}$ & $81.9 \pm 8.7(2.0)$ \\
\hline - Mandarin & $59.1 \pm 2.8^{\mathrm{a}}$ & $40.7 \pm 0.4^{\mathrm{a}}$ & $44.6 \pm 13.1^{\mathrm{a}}$ & $61.2 \pm 5.1(2.0)$ \\
\hline - Orange & $44.4 \pm 0.8^{b}$ & $37.6 \pm 5.4^{\mathrm{a}}$ & $44.8 \pm 14.2^{\mathrm{a}}$ & $53.2 \pm 4.5(2.0)$ \\
\hline \multicolumn{5}{|l|}{ Stone fruits } \\
\hline - Apricot & $70.9 \pm 2.5^{\mathrm{a}}$ & $85.9 \pm 2.8^{b}$ & $100.9 \pm 4.2^{b}$ & $100.9 \pm 4.2(0.2)$ \\
\hline - Cherry & $76.0 \pm 2.2^{\mathrm{a}}$ & $87.9 \pm 2.2^{b}$ & $90.5 \pm 10.4^{b}$ & Not detected (0.02) \\
\hline - Peach & $68.3 \pm 2.0^{\mathrm{a}}$ & $59.8 \pm 3.4^{\mathrm{a}}$ & $60.0 \pm 17.7^{\mathrm{a}}$ & $60.0 \pm 17.7(0.2)$ \\
\hline
\end{tabular}

Leafy vegetables

- Lettuce

$60.3 \pm 2.1^{\mathrm{a}}$

$70.9 \pm 0.7^{\mathrm{a}}$

$76.5 \pm 13.7^{\mathrm{a}}$

Not detected (0.02)

- Chicory

$73.9 \pm 4.5^{\mathrm{b}}$

$76.2 \pm 2.4^{\mathrm{b}}$

$71.0 \pm 9.4^{\mathrm{a}}$

Not detected (0.02)

- Spinach

$53.9 \pm 1.3^{\mathrm{a}}$

$68.2 \pm 1.6^{\mathrm{a}}$

$73.9 \pm 8.6^{\mathrm{a}}$

Not detected (0.02)

Fruiting vegetables

- Cucumber

$84.8 \pm 3.4^{b}$

$106.4 \pm 4.9^{\mathrm{a}}$

$104.5 \pm 3.4^{\mathrm{a}}$

Not detected (0.02)

- Pepper

$72.0 \pm 4.1^{\mathrm{a}}$

$102.3 \pm 2.8^{\mathrm{a}}$

$112.2 \pm 0.5^{\mathrm{a}}$

Not detected (0.02)

- Tomato

$97.1 \pm 4.8^{\mathrm{c}}$

$93.9 \pm 4.0^{\mathrm{a}}$

$109.5 \pm 1.3^{\mathrm{a}}$

$109.5 \pm 1.3(0.2)$

\section{Various}

- Kiwi fruits

$58.7 \pm 3.4 \quad 53.5 \pm 4.1$

$76.6 \pm 3.7$

Not detected (0.02)

- Table grapes

$\mathbf{9 1 . 8} \pm \mathbf{2 . 8}$

$98.0 \pm 2.8$

$98.0 \pm 4.6$

$\mathbf{9 8 . 0} \pm \mathbf{2 . 8}(0.5)$

- Strawberries

$60.5 \pm 1.6$

$86.4 \pm 2.1$

$81.4 \pm 5.0$

$292.6 \pm 8.9(0.02)$

$38 \mathrm{a}, \mathrm{b}$, c: means within a plant product category and fortification level lacking a

39 common superscript letter are different $(\mathrm{p}<0.05)$. 
$40 *$ Some MRLs are equal to one of the rest examined concentrations (i.e. 0.2 and

$410.5 \mathrm{mgkg}^{-1}$ ). For this reason the respective recoveries appear in two columns of the 42 same row in the Table 